\title{
Investigation of Wear Behavior of Precipitation-Strengthened Nickel-Copper Based K-500 Alloy Produced by Powder Metallurgy
}

\author{
U. ESGIN ${ }^{a}$, D. ÖZYÜREK ${ }^{a}$ AND H. KAYA ${ }^{b, *}$ \\ ${ }^{a}$ Karabuk University, Technology Faculty, Department of Manufacturing Engineering, 78050 Karabuk, Turkey \\ ${ }^{b}$ Kocaeli University, Asim Kocabiyik Vocational School of Higher Education, Department of Machine, \\ 41800 Kocaeli, Turkey
}

\begin{abstract}
The present study investigates the effects of the ageing parameters of the precipitation-strengthened nickelcopper based K-500 alloy produced by powder metallurgy on the wear behavior of the alloy. After the cold pressing the prepared alloy powders under $600 \mathrm{MPa}$ pressure, the samples were sintered under vacuum $\left(10^{-6} \mathrm{mbar}\right)$ at $1150^{\circ} \mathrm{C}$ for $2 \mathrm{~h}$ and then cooled in the furnace. Produced K-500 alloy samples were taken into solution at $980^{\circ} \mathrm{C}$ for $1 \mathrm{~h}$ and quenched. Ageing process was carried out at $480^{\circ} \mathrm{C}$ for four different time periods $(6,8,10$, and $12 \mathrm{~h}$ ). Aged samples were examined transmission electron microscope (TEM + EDS), X-ray diffraction (XRD), hardness and density measurements. The wear tests were carried out at $1 \mathrm{~ms}^{-1}$ constant sliding speed, under $40 \mathrm{~N}$ load and for five different sliding distances $(400-2000 \mathrm{~m})$. The results showed that there is $\gamma^{\prime} \mathrm{Ni}_{3}(\mathrm{Al}$, Ti) inter-metallic phase coexisting with $\mathrm{Al}_{0.9} \mathrm{Ni}_{4.22}, \mathrm{AlNi}_{3}$ and $\mathrm{NiO}$ phases. According to the hardness measurements, the highest hardness values were obtained with samples aged for $8 \mathrm{~h}$. In wear tests with $2000 \mathrm{~m}$ sliding distance, the lowest weight loss was observed for the samples aged for $8 \mathrm{~h}$.
\end{abstract}

DOI: 10.12693/APhysPolA.129.544

PACS/topics: 81.40.Pq

\section{Introduction}

Nickel-copper based Monel alloy K-500, containing small amounts of iron, manganese, aluminum and titanium is an age hardenable alloy. The second phase coherent $\mathrm{Ni}_{3}(\mathrm{Al}, \mathrm{Ti})$ precipitates formed in the structure are responsible for increasing strength in the ageing heat treatment. The most important characteristic of this alloy is that it exhibits high corrosion-resistance in different environments like other Monel alloys. These materials are a preferred material group in applications in chemical, automotive and marine industries due to their high resistance to corrosive environments. Because of their corrosion-resistance and mechanical properties, Monel alloys can be compared with stainless steel materials [1-7]. Another significant property of these alloys is their mechanical behaviors. Evgenov [8] reported that K-500 alloys produced by casting method exhibits high corrosion-resistance, wear behavior and high deformation capacity. Alloy elements in the composition of the K-500 alloy are effective on mechanical properties, particularly on the wear behavior. The most prominent factor that contributes to wear behavior is the amount of silicon content. Silicon in the structure causes the formation of an oxide layer on the surface, which increases the adhesive strength of the alloy especially in operating conditions under friction $[9,10]$. Although the K-500 alloy is widely used in the industry, it was seen that there is no detailed

*corresponding author; e-mail: hasan.kaya@kocaeli.edu.tr investigation of the effects of ageing parameters on the wear behavior. Therefore, in this study, a systematic analysis was performed on the interaction between the second phase formed in structure of the K-500 alloy with ageing and effects on microstructure and wear behavior of this alloy.

\section{Materials and method}

In this study, K-500 alloys were produced by $\mathrm{P} / \mathrm{M}$ method and then ageing heat treatment was carried out. The chemical composition of the produced K-500 alloy was given in Table I.

TABLE I

Chemical composition of Monel K-500 alloys.

\begin{tabular}{c|c|c|c|c|c|c|c|c}
\hline \hline \multirow{2}{*}{ Alloy } & \multicolumn{7}{|c}{ Element [wt\%] } \\
\cline { 2 - 9 } & $\mathrm{Cu}$ & $\mathrm{Ni}$ & $\mathrm{Si}$ & $\mathrm{Fe}$ & $\mathrm{Mn}$ & $\mathrm{C}$ & $\mathrm{Al}$ & $\mathrm{Ti}$ \\
\hline $\begin{array}{c}\text { Monel } \\
\text { K-500 }\end{array}$ & 28.75 & 63 & 0.5 & 2 & 1.5 & 0.25 & 3.15 & 0.85
\end{tabular}

In the production process of the K-500 alloy, elemental powders were weighted by a scale with $1 / 10000 \mathrm{~g}$ precision (wt\%) and they were mixed through T2F GlennMills Model Turbula Shaker mixer at $67 \mathrm{rpm}$ for $60 \mathrm{~min}$. After the mixing process, alloy powders were cold-pressed $(600 \mathrm{MPa})$ to produce green compact samples of $12 \times$ 6-7 mm dimension. These green compact samples were sintered at $1150^{\circ} \mathrm{C}$ (under $10^{-6}$ mbar vacuum) for $2 \mathrm{~h}$, and then they were cooled down to room temperature in the furnace. Sintered specimens were aged at $480^{\circ} \mathrm{C}$ for four different times $(6,8,10$, and $12 \mathrm{~h})$. After specimens were kept in the solution process at $980^{\circ} \mathrm{C}$ for $1 \mathrm{~h}$, 
they were quenched. Aging processing was carried out at two stages. In the first stage, samples were kept at $595{ }^{\circ} \mathrm{C}$ for $16 \mathrm{~h}$. Then the furnace temperature was reduced to $540{ }^{\circ} \mathrm{C}$ and samples were kept at this temperature for $6 \mathrm{~h}$. At the second stage, samples were kept at $480^{\circ} \mathrm{C}$ for $6,8,10$, and $12 \mathrm{~h}$ for ageing. After ageing was completed, densities were measured according to the Archimedes principle. Hardness measurements $\left(\mathrm{HMV}_{0.5}\right)$ were carried out using Shimadzu (HMV-2). Hardness values were determined by calculating the mean value of five measurements taken from each sample.

For characterization studies, the aged samples were subjected to standard metallographic processes and etched by $50 \mathrm{ml}$ glycerol, $20 \mathrm{ml} \mathrm{HCl}$ acid and $10 \mathrm{ml} \mathrm{HNO}_{3}$ for 5-10 min. The prepared samples were characterized through scanning electron microscope (SEM + EDS/FEI Quanta 250), transmission electron microscope (TEM) FEI Tecnai G2 F30 (200 kV) and X-ray diffraction (XRD) Rigaku (D-MAX RIN-2200 Series X-RAY Diffractometer). Wear tests were carried out on pin-on-disc typewear device according to the ASTM-G99-05 standard. All samples were ground using 1200 grade $\mathrm{SiC}$ sandpaper and polished with $6 \mu \mathrm{m}$ diamond paste before the wear tests to ensure full contact between the abrasive steel disc and sample surfaces. In the wear tests, $40 \mathrm{~N}$ load, five different sliding distances (400-2000 m) and $1 \mathrm{~ms}^{-1}$, sliding speed were used. Before the tests, abrasive disc and sample surfaces were cleaned with acetone. Following the wear tests, the worn surfaces were examined with SEM.

\section{Results and discussion}

\subsection{Microstructural characterization}

Microstructure SEM images of K-500 alloy, aged for different times $(6,8,10$, and $12 \mathrm{~h}$ ) are given in Fig. 1 and EDS analysis results are presented in Table II. As it can be understood from the SEM images, there are pores in the structure (dark spherical areas). After the ageing process, second phase precipitates expected to be formed in structure were not found in the SEM images. Therefore, they were examined with TEM to observed $\gamma^{\prime}$ precipitations. Bright field TEM image and SAD pattern elemental analysis of the $8 \mathrm{~h}$ aged Monel K-500 alloy are given in Fig. 2.

\section{TABLE II}

The EDS results of the aged K-500 alloys.

\begin{tabular}{c|c|c|c|c|c|c|c|c}
\hline \hline & & \multicolumn{7}{|c}{ Element [wt\%] } \\
\cline { 3 - 8 } Figure & Location & $\mathrm{O}$ & $\mathrm{Al}$ & $\mathrm{Si}$ & $\mathrm{Mn}$ & $\mathrm{Fe}$ & $\mathrm{Ni}$ & $\mathrm{Cu}$ \\
\hline 1b & 2 & 0.64 & 1.91 & 1.13 & 1.01 & - & 53.08 & 42.22 \\
1b & 3 & 1.59 & 1.75 & 0.88 & - & 1.75 & 54.02 & 40.02
\end{tabular}

According to bright field images of the aged K-500 alloy given in Fig. 2a and b, it was observed that $\gamma^{\prime} \mathrm{Ni}_{3}(\mathrm{Al}, \mathrm{Ti})$ precipitations (spherical formed) and $\mathrm{Ni}$ and $\mathrm{Cu}$-rich precipitations were formed during the ageing process. As a result of the SAD pattern region element analysis seen in Fig. 2c, it was understood that $\mathrm{Ni}$ and $\mathrm{Cu}$ concentrations decrease while $\mathrm{Al}$ concentration was increased
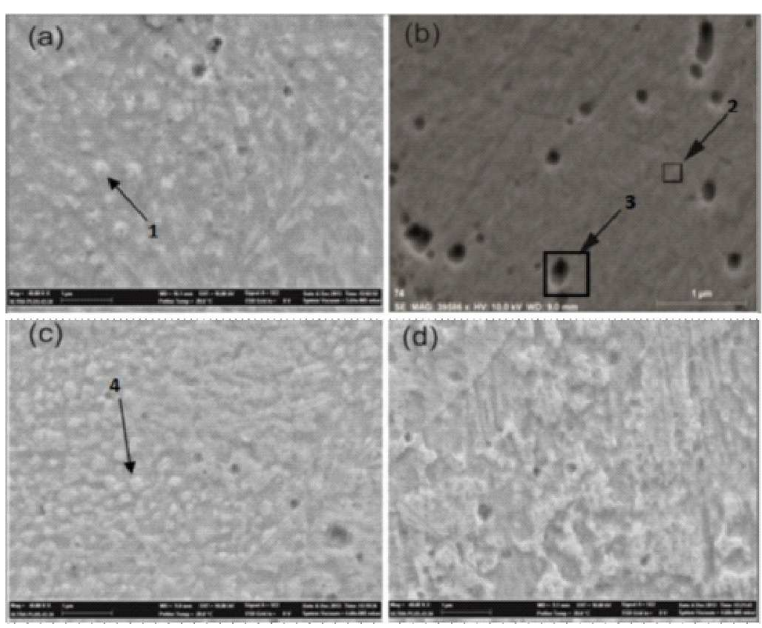

Fig. 1. The SEM images of the K-500 alloy samples aged for different times: (a) $6 \mathrm{~h}$, (b) $8 \mathrm{~h}$, (c) $10 \mathrm{~h}$, and (d) $12 \mathrm{~h}$.
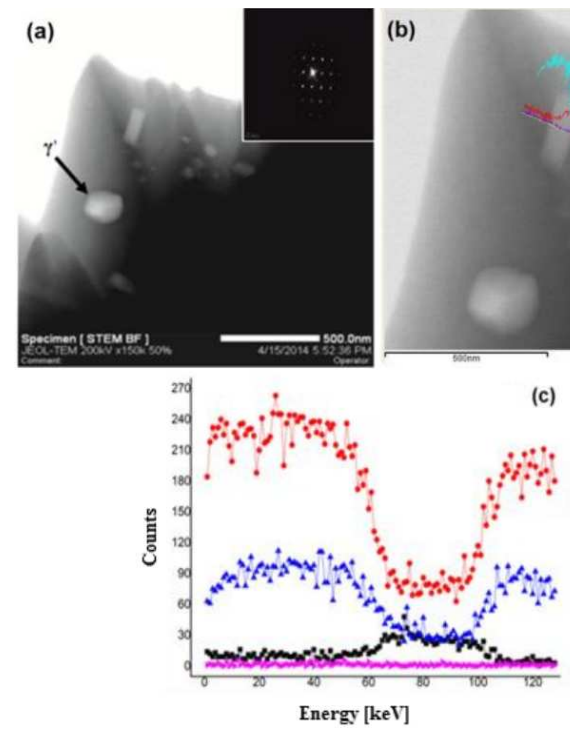

Fig. 2. Bright field TEM image (a), (b) and the SAD pattern elemental analysis (c) of $8 \mathrm{~h}$ aged K-500 alloy.

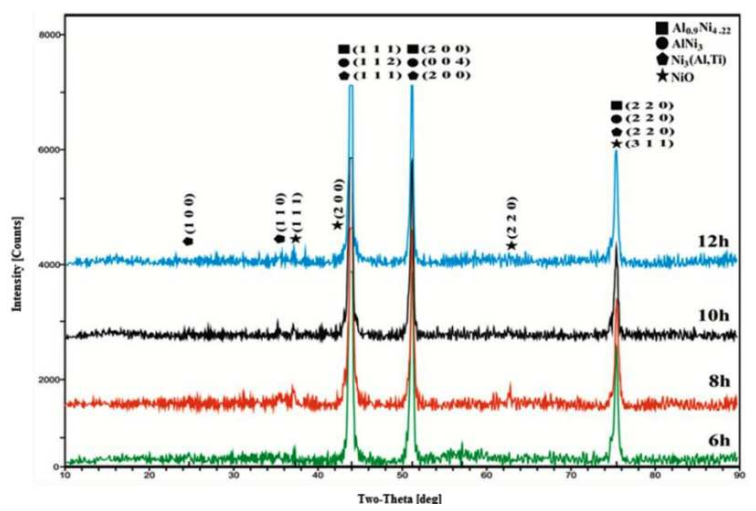

Fig. 3. XRD results of K-500 alloys aged for different times. 
from the matrix structure to the precipitation. A small amount of $\mathrm{Ti}$ was also observed in the structure. In the bright field TEM image, $\gamma^{\prime} \mathrm{Ni}_{3}(\mathrm{Al}, \mathrm{Ti})$ phase was observed which was formed in the structure during ageing and it is the most important phase of the nickel-copperbased alloys which contributes to increasing strength of the Ni-based K-500 alloys. It occurs through the second phase precipitation during the ageing in supersaturated solid solution due to taking into solution and quenching. After quenching of the supersaturated solid solution, $\gamma^{\prime}$ phase $\left(\mathrm{Ni}_{3}(\mathrm{Al}, \mathrm{Ti})\right)$ precipitates are formed in the structure. This phase is the main reason of the strength of K-500 alloy. Therefore, as the amount of $\mathrm{Al}$ and $\mathrm{Ti}$ increases in nickel-based alloys, strength of the alloy increases as well [11]. XRD results of the K-500 alloys aged for different times are given in Fig. 3.

$\mathrm{XRD}$ results in Fig. 3 show the same phases formed in the aged K-500 alloy. It is clear that $\mathrm{Ni}_{3}(\mathrm{Al}, \mathrm{Ti})$ precipitations occurred in the structure as a result of the ageing process. It was also observed that $\mathrm{Al}_{0.9} \mathrm{Ni}_{4.22}$, $\mathrm{AlNi}_{3}$ and $\mathrm{NiO}$ intermetallic phases occurred in K-500 alloy. It is considered that the $\mathrm{NiO}$ phase formed in the structure during the powder mixing or sintering processes. In Fig. 4, density and hardness changes of K-500 alloys aged for different times are given.
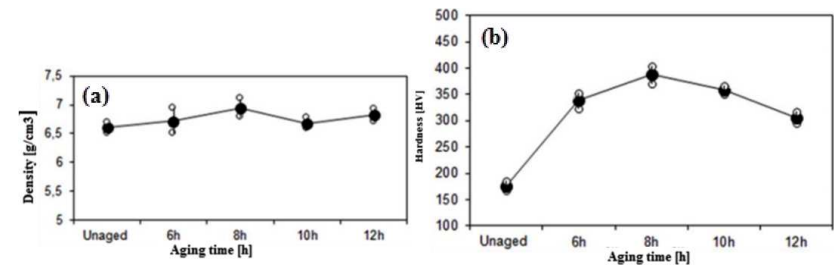

Fig. 4. Density (a) and hardness (b) changes in K-500 alloys aged for different times.

It can be observed from Fig. 4 that density changes of aged K-500 alloys for different ageing times are close to each other. After the ageing process, the highest density value is obtained for the samples aged for $8 \mathrm{~h}$ while the lowest density was observed for non-aged K-500 alloy. Higher density result can be attributed to long and gradual ageing process which decreases the volume of the pores within the structure. Comparing the hardness results of K-500 alloys aged for different times, it can be argued that increasing ageing time increases the hardness of the material. $\gamma^{\prime}$ precipitates $\mathrm{Ni}_{3}(\mathrm{Al}, \mathrm{Ti})$ formed through ageing of the K-500 alloys are the most important factor for increasing hardness. Since $\gamma^{\prime}$ precipitations formed during the initial stages of the ageing process are small (GP1 and GP2 zones), dislocation movements are not prevented adequately and therefore the increase observed in hardness is limited. As the ageing time increases, the precipitate size also increases and dislocation movements become more difficult which improves hardness. Since the precipitate dimensions increase in the alloy aged for $6 \mathrm{~h}$, the obtained hardness is higher than that of non-aged alloy. The highest hardness value was measured with the K-500 alloy which was aged for 8 h. K-500 alloys are different from other $\mathrm{Ni}-\mathrm{Al}$ and $\mathrm{Ni}-\mathrm{Ti}$ alloys. In this alloy, $\gamma^{\prime}$ precipitations can easily be obtained in structure through ageing process. Dey and Mukhopadhyay [12] reported that $\gamma^{\prime}$ precipitations formed in the structure through ageing process exhibit very little or no change up to $700^{\circ} \mathrm{C}$ temperature. Therefore, under long term service at high temperature conditions, $\gamma^{\prime}$ precipitations could change. It is observed that there is slight decrease on the hardness values of the K-500 alloy aged for $10 \mathrm{~h}$ and $12 \mathrm{~h}$. This decreasing hardness of the alloy can be explained by the dimensional change in $\gamma^{\prime}$ precipitations due to over-ageing [12-14].

\subsection{Wear test results}

Weight losses and wear rates of the aged K-500 alloy under conditions of $1 \mathrm{~ms}^{-1}$ sliding speed, $40 \mathrm{~N}$ load and five different sliding distances (400-2000 m) are given in Fig. 5.
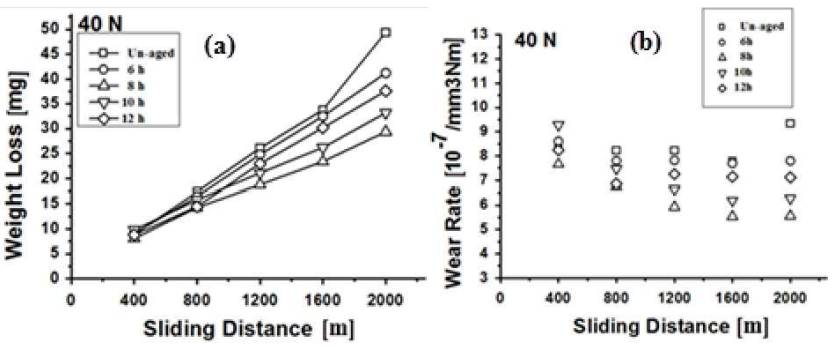

Fig. 5. Weight loss (a) and wear rate (b) of aged K-500 alloy.

According to Fig. 5, it is observed that weight loss of the K-500 alloy increases as the sliding distance increases. Wear test results conducted under $40 \mathrm{~N}$ load revealed that the lowest weight loss was achieved by the K-500 alloy which was aged for $8 \mathrm{~h}$; and the highest weight loss was with the non-aged alloys. The reason for this difference in weight losses is the $\gamma^{\prime}$ phase created through ageing process. Based on the hardness results given in Fig. 4, it can be concluded that as the hardness values of the alloys increase, their weight loss values decrease. The reason for higher weight loss values of K-500 alloys age hardened for $10 \mathrm{~h}$ and $12 \mathrm{~h}$ than the ones aged for $8 \mathrm{~h}$ was that precipitations within the structure expanded and caused excessive ageing in $\gamma^{\prime}$ precipitation. According to the wear rates of the aged K-500 alloy, it was observed that the highest wear rate was given by the K-500 alloys that were not aged. The lowest wear rate was measured with K-500 alloys aged for $8 \mathrm{~h}$. Wear rate values are in great correlation with weight loss and hardness results of alloys. Figure 6 shows the SEM images of the K-500 alloys' surfaces incurred for wear tests for different times.

According to SEM images of the worn surfaces of the K-500 alloys aged under $40 \mathrm{~N}$ loading, it was possible to observe worn marks. It was understood from the 


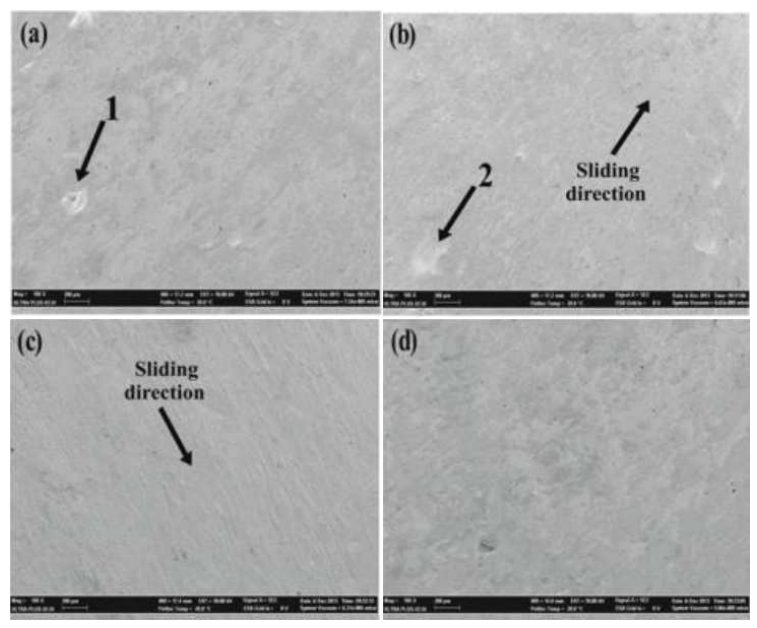

Fig. 6. The SEM images of K-500 alloys incurred wear test under $40 \mathrm{~N}$ for different time periods: (a) $6 \mathrm{~h}$, (b) $8 \mathrm{~h},(\mathrm{c}) 10 \mathrm{~h}$, and (d) $12 \mathrm{~h}$.

images of the worn surfaces of the age hardened alloys that smearing was formed on the surface (on points of 1 and 2), and material transportation occurred. Therefore, it can be said that wearing mechanism occurring during these wear tests was adhesive wear mechanism [15].

\section{Conclusion}

In this study, microstructures and wear behaviors of the K-500 alloy were investigated which was manufactured by $\mathrm{P} / \mathrm{M}$ method and aged. Results of the conducted study are summarized below:

- It was determined that $\gamma^{\prime} \mathrm{Ni}_{3}(\mathrm{Al}, \mathrm{Ti})$ intermetallic phase was formed in the K-500 alloy that was aged for different times.

- XRD results showed that $\mathrm{Al}_{0.9} \mathrm{Ni}_{4.22}, \mathrm{AlNi}_{3}$ and $\mathrm{NiO}$ phases were formed at the end of the ageing process besides the $\gamma^{\prime} \mathrm{Ni}_{3}(\mathrm{Al}, \mathrm{Ti})$ intermetallic.

- It was determined that densities of K-500 alloys aged for different times were close to each other and all of them have higher densities than non-aged alloys.

- The highest hardness values was measured with the $8 \mathrm{~h}$ aged K-500 alloy and the highest weight losses on sliding distances was measured with the specimens that were age hardened for $8 \mathrm{~h}$.
- The lowest wear rate value in wear tests was measured with K-500 alloys age hardened for $8 \mathrm{~h}$.

- It was determined that the second phase precipitations formed as a result of the ageing heat treatment are effective on hardness, density, weight loss and wear rate.

\section{Acknowledgments}

The authors are pleased to acknowledge the financial support for this study from Scientific Research Projects Department of Karabuk University (KBÜ-BAP-13/1-Y030).

\section{References}

[1] B. Chen, J. Wang, F. Yan, Tribol. Lett. 42, 17 (2011).

[2] R.J.K. Wood, Wear 261, 1012 (2006).

[3] N. Espallargas, S. Mischler, Tribol. Int. 43, 1209 (2010).

[4] K.C. Tekin, U. Malayoglu, Tribol. Lett. 37, 563 (2010).

[5] A. Yano, A. Sakanishi, F. Takahashi, S. Shirai, Y. Uchida, K. Fujita, F. Kikkawa, K. Fujioka, T. Kawazoe, K. Saki, Y. Yamamoto, Tribol. Trans. 50, 13 (2007).

[6] E. Boese, J. Rothig, I. Garz, H. Schmidtchen, Mater. Corros. 49, 98 (1998).

[7] S.W. Watson, F.J. Friedersdorf, B.W. Madsen, S.D. Cramer, Wear 181, 476 (1995).

[8] A.G. Evgenov, V.A. Kalitsev, A.M. Rogalev, Metallurgist 57, 736 (2013).

[9] L.E. Shoesmaker, G.D. Simith, JOM 58, 22 (2006).

[10] A.G. Evgenov, G.I. Morozova, V.I. Lukin, Met. Sci. Heat Treat. 48, 364 (2006).

[11] O.S. Es-Said, K. Zakharia, Z. Zakharia, C. Ventura, D. Pfost, P. Crawford, T. Ward, D. Raizk, J. Foyos, R. Marloth, Eng. Fail. Anal. 7, 323 (2000).

[12] G.K. Dey, P. Mukhopadhyay, Mater. Sci. Eng. 84, 177 (1986).

[13] G.K. Dey, R. Tewari, P. Rao, S.L. Wadekar, P. Mukhopadhyay, Metall. Trans. A 24, 2709 (1993).

[14] J.H. Ai, H.M. Ha, R.P. Gangloff, J.R. Scully, Acta Mater. 61, 3186 (2013).

[15] I. Saglam, D. Özyürek, K. Cetinkaya, Bull. Mater. Sci. 34, 1465 (2011). 